\title{
The Comparative Effect of Computer-Assisted and Paper-and-Pencil Concept Mapping on Learning Motivation and Achievement
}

\author{
Chei-Chang Chiou
}

\begin{abstract}
This paper compared the effect of different concept mapping on students' learning motivation and academic achievement. A pretest-posttest control group experimental design was employed. The participants were 151 students from the Department of Accounting Information at a private university in central Taiwan who were taking an advanced accounting course. An effect size and analysis of covariance were used to analyze experimental results. Experimental results show that the two computer-assisted concept mapping techniques (construct-on-scaffold and construct-by-self) are more beneficial to students' learning motivation and academic achievement than traditional paper-and-pencil concept mapping and textbook exercise methods. In addition, traditional paper-and-pencil concept mapping is better than the textbook exercise method. However, no significant differences existed between the two computer-assisted concept mapping techniques.
\end{abstract}

Index Terms-Construct-by-self computer-assisted concept mapping, construct-on-scaffold computer-assisted concept mapping, learning achievement, learning motivation, paper-and-pencil concept mapping.

\section{INTRODUCTION}

This paper investigated the influence of a particular learning strategy, computer-assisted concept mapping, on students' learning. It was anticipated the computer-assisted concept mapping would not only have a positive impact on students' academic achievement, but would impact learning motivation as well.

Learning motivation is the driving factor in catalyzing the will and desire to succeed or to achieve certain learning goals [1]. Psychologists and educators have long considered the role of motivation in student achievement and learning [2]. Many researches proved that students' learning motivation is positive related to their learning achievement [2]-[5]. Therefore, how to improve students' learning motivation and then enhance their academic achievement is a concerned problem by academic researchers and practical teachers.

A concept map is a schematic device for representing interrelationships among a set of concept meanings embedded in a framework of propositions and hierarchical, node-link diagrams that represent cognitive knowledge of individuals in visual or graphic forms [6]. Concept mapping

Manuscript received April 9, 2014; revised July 9, 2014. This work was supported in part by the National Science Council of the Republic of China under contract No. 101-2410-H-018-026.

Chei-Chang Chiou is with the Department of Accounting, National Changhua University of Education, Changhua 500, Taiwan (e-mail: ccchiou@cc.ncue.edu.tw). is a teaching and learning strategy that helps students organize concept information [7]. When constructing a concept map, students would enter the mapping activities with the goal of illustrating interrelationship among concepts on the map. This proximal and challenging goal would support students in organizing their efforts as they completed their concept maps [8]. Therefore, we anticipated that students could improve their motivation from concept mapping activities and then enhanced their academic achievement. However, some researches have proved that paper-and-pencil concept mapping can improve students' learning motivation [8] while some researches pointed out that paper-and-pencil concept mapping may reduce students' learning motivation [9].

In fact, paper-and-pencil concept mapping have some disadvantages such as inconvenient feedback, difficult for novices and difficult to revise [7], [10], [11]. These disadvantages may make novices be frustrated and reduce their motivation to learn with concept mapping strategy. To solve these problems, researchers used computer-assisted concept mapping systems such as Inspiration and achieved positive academic outcomes [7], [11]. However, some drawbacks still exist in computer-assisted concept mapping such as novices may easily get frustrated, feedbacks from experts are difficult and students' learning is easily not focused back on the subject in the mapping process [10] and thus may decrease students' learning motivation [12]. Therefore, some researchers proposed ideas of construct-on-scaffold concept mapping and pointed out that construct-on-scaffold concept mapping produces better learning achievement [10], [13]. However, to date, no study investigates whether different concept mapping strategies have different benefit for students' learning motivation and academic achievement. Therefore, this paper compared the effect of different computer-assisted concept mapping (construct-on-scaffold and construct-by-self) (CACOS and CACBS), paper-and-pencil concept mapping (PAP) and traditional textbook exercise (TTE) methods on learning motivation and academic achievement.

\section{METHOD}

\section{A. Experimental Design and Participants}

A pretest-posttest control group design was used. Participants were 151 accounting and information students from four classes (43 male and 108 female) at one private technical university in Taiwan. Students were randomly assigned to four groups (three experimental groups include 
CACOS, CACBS and PAP, and one control TTE group). All students were administered to learning motivation and academic achievement pretests before the experiment and they also completed learning motivation and academic achievement posttests at the end of the experiment. Four classes were taught by the same instructor, who is an experienced teacher teaching Advanced Accounting for six years.

\section{B. Instruments}

\section{1) Learning motivation scale}

A seven-point Likert scale with 81 items instrument called Motivated Strategies for Learning Questionnaire (MSLQ) developed by Pintrich, Smith and McKeachie [4] were used to assess students' learning motivation for adopting four different teaching strategies. One hundred and fifty one students participated in this study and learning motivation scale in this study with Cronbach's alpha reliability coefficient ranged from 0.78 to 0.92 .

\section{2) Accounting achievement test}

The pretest and posttest evaluated the accounting academic achievement of students. The four groups of students took the same pretest before the experiment. The pretest assessed whether students had the same level of accounting knowledge prior to the experiment. After the experiment, these students took the posttest to assess their learning achievement using different concept mapping strategies. An analysis of covariance was then used to analyze the experimental results. The 40 items on the accounting achievement test were selected from the course textbook individually and each item was assigned a possible score of 2.5 points. The questions for both tests were examined using a two-way specification table with sections for knowledge, comprehension, application, and analysis. The KR-20 reliability for the pretest and posttest was 0.81 and 0.84 , respectively.

\section{Procedure}

During week 1 , the instructor introduced the course. The first two chapters in the textbook were taught by the same instructor during weeks 2,3 , and 4 . In week 5, the two-hour pretest was administrated as the accounting achievement and learning motivation pretests to assess students' basic accounting knowledge and learning motivation. Four-group teaching experimental research was then conducted. Students in each class were randomly assigned to either CACOS, CACBS, PAP or TTE groups. All computer groups constructed concept maps by using Inspiration software. CACOS group completed blank concepts or linking language on semi-completed expert concept maps. CACBS group used Inspiration software to freely complete their own work on given accounting concepts by the instructor. PAP group completed their accounting concept maps by using paper-and-pencil method. However, the TTE control group practiced textbook exercises during the experiment.

All participants received the same one way instructional teaching method based on teacher self-prepared teaching materials in formal class. Teaching experiment was conducted during additional two TA hours for every group. Three concept map groups (CACOS, CACBS, PAP) first learned concept map strategy, theory about concept maps, Inspiration software (only for computer groups), and discussed related issues on concept maps.

In the following week, experimental group students constructed their own concept maps based on contents learned and the instructor, researcher, and teaching assistants were around to answer questions related to concept maps and advanced accounting. Students' concept maps were graded by the instructor, researcher, and teaching assistants following guideline by Novak and Gowin [14]. Misconception and insufficient horizontal cross links were found during the grading process. Remedy teaching were taken place by returning student homework for corrections and discussion on accounting misconception. Students corrected their prior homework and continued new unit learned and these kinds of process go back and forth till the end of experiment. After the experiment, students have their own personal integrated accounting concepts for review on posttests. The total experimental period took 8 weeks of 16 hours.

During two hour experimental period, TTE group students practiced textbook questions and some were selected to write their answers in front of the class and the teacher then discussed and provided correct answers. The process will go back and forth till the end of the experiment. At the end, three experimental groups and one control group completed a two-hour achievement and motivation posttest in order to compare results.

\section{RESULTS}

\section{A. Effects of Different Concept Mapping Techniques on Learning Motivation}

The average learning motivation pretest and posttest score and effect size for each group were as follows: the CACOS group, 294.37, 409.45 and 1.42; the CACBS group, 291, 409.11, and 1.55; the PAP group, 299.22, 320.67, and 0.29; and the TTE group 303.29, 254.07, and -0.72 (Table I). In measuring learning motivation, effect size for groups from best to worst was CACBS, CACOS, PAP, and TTE. Additionally, according to Cohen [15], the impact of computer-assisted concept mapping on learning motivation is large and the effectiveness of paper-and-pencil concept mapping is medium. Analysis of covariance (ANCOVA) (Table II) indicates that differed significantly among groups $(F=63.40, p<.01)$; thus, different teaching strategies impacted learning motivation after controlling pre-test. Post hoc comparisons using Fisher's least significant difference (LSD) procedure indicate that students in three concept mapping groups have significantly better learning motivation $(t=11.58, p<.01 ; t=11.63, p<.01 ; t=4.91, p<.01)$ than TTE group. Both computer-assisted concept mapping groups (CACOS and CACBS) performed significantly better in learning motivation $(t=6.66, p<.01 ; t=6.72, p<.01)$ than the PAP group. However, no significant difference $(t=-0.06$, $p>0.05)$ in learning motivation existed between the CACOS and CACBS groups. These experimental results underline three important points. First, concept mapping can elevate students' learning motivation more than traditional textbook 
exercises. Second, students using computer-assisted concept mapping have significantly higher learning motivation than those using paper and pencil. Third, no significant difference existed in learning motivation between the two groups using computer-assisted concept mapping.

TABLE I: DESCRIPTIVE STATISTICS: CACOS, CACBS, PAP, AND TTE GROUPS

\begin{tabular}{|c|c|c|c|c|c|c|c|c|}
\hline \multirow{2}{*}{ Motivation } & \multicolumn{2}{|l|}{ CACOS $^{\mathrm{a}}$} & \multicolumn{2}{|l|}{ CACBS } & \multicolumn{2}{|l|}{ PAP } & \multicolumn{2}{|l|}{ TTE } \\
\hline & Mean & $S D$ & Mean & $S D$ & Mean & $S D$ & Mean & $S D$ \\
\hline Post-test & 409.45 & 60.43 & 409.11 & 65.51 & 20.67 & 64.47 & 254.07 & 64.13 \\
\hline Pre-test & 294.37 & 81.36 & 291.00 & 76.04 & 99.22 & 73.04 & 303.29 & 68.08 \\
\hline Effect size $^{\mathrm{b}}$ & 1.42 & - & 1.55 & - & 0.29 & - & -0.72 & - \\
\hline $\mathrm{N}^{\mathrm{c}}$ & \multicolumn{2}{|c|}{38} & \multicolumn{2}{|c|}{38} & \multicolumn{2}{|c|}{36} & \multicolumn{2}{|c|}{35} \\
\hline
\end{tabular}

a. CACOS represents computer-assisted construct-on-scaffold group, CACBS represents computer-assisted construct-by-self group, PAP represents paper-and-pencil group, and TTE represents traditional textbook exercises group.

b. Effect size measures the influence of the learning strategy and is computed as the mean motivation score of the post-test minus the mean motivation score of the pre-test, divided by the standard deviation of the pre-test.

c. $\mathrm{N}$ indicates the number of student.

TABLE II: ANALYSIS OF COVARIANCE IN LEARNING MOTIVATION POSTTEST SCORES FOR FOUR GROUPS

\begin{tabular}{|c|c|c|c|c|}
\hline \multirow{2}{*}{ Source of variance } & \multicolumn{4}{|c|}{ Analysis of covariance } \\
\hline & $S S$ & lf & $M S$ & $F$ \\
\hline \multirow{2}{*}{$\begin{array}{l}\text { Model } \\
\text { Group }\end{array}$} & 715717.06 & 4 & 178929.27 & $52.55^{* * \mathrm{~d}}$ \\
\hline & 647606.24 & 3 & 215868.75 & $63.40 * *$ \\
\hline Covariate & 95675.81 & 1 & 95675.81 & $28.10^{* *}$ \\
\hline Error & 483494.24 & 142 & 3404.89 & \\
\hline \multirow{2}{*}{ Groups differences } & \multicolumn{4}{|c|}{ A post hoc comparison } \\
\hline & \multicolumn{2}{|c|}{ Difference in means } & \multicolumn{2}{|c|}{$t$} \\
\hline CACOS-CACBS & \multicolumn{2}{|c|}{-.82} & \multicolumn{2}{|c|}{-0.06} \\
\hline CACOS-PAP & \multicolumn{2}{|c|}{90.46} & \multicolumn{2}{|c|}{$6.66^{* *}$} \\
\hline CACBS-PAP & \multicolumn{2}{|c|}{91.28} & \multicolumn{2}{|c|}{$6.72 * *$} \\
\hline CACOS-TTE & \multicolumn{2}{|c|}{158.45} & \multicolumn{2}{|c|}{$11.58 * *$} \\
\hline CACBS-TTE & \multicolumn{2}{|c|}{159.27} & \multicolumn{2}{|c|}{$11.63^{* *}$} \\
\hline PAP-TTE & \multicolumn{2}{|c|}{68.00} & \multicolumn{2}{|c|}{$4.91 * *$} \\
\hline
\end{tabular}

TABLE III: DESCRIPTIVE STATISTICS: CACOS, CACBS, PAP, AND TTE GROUPS

\begin{tabular}{|c|c|c|c|c|c|c|c|c|}
\hline \multirow{2}{*}{ Motivation } & \multicolumn{2}{|c|}{$\mathrm{CACOS}^{\mathrm{e}}$} & \multicolumn{2}{|c|}{ CACBS } & \multicolumn{2}{|c|}{ PAP } & \multicolumn{2}{|c|}{ TTE } \\
\hline & Mean & $S D$ & Mean & $S D$ & Mean & $S D$ & Mean & $S D$ \\
\hline Post-test & 81.32 & 12.23 & 80.62 & 13.18 & 63.89 & 12.94 & 0.43 & 13.28 \\
\hline Pre-test & 49.54 & 14.33 & 48.83 & 13.23 & 50.35 & 12.76 & 0.93 & 11.82 \\
\hline Effect size ${ }^{f}$ & 2.22 & - & 2.40 & - & 1.06 & - & -0.04 & - \\
\hline $\mathrm{N}^{\mathrm{g}}$ & \multicolumn{2}{|c|}{38} & \multicolumn{2}{|c|}{38} & \multicolumn{2}{|c|}{36} & \multicolumn{2}{|c|}{35} \\
\hline \multicolumn{9}{|c|}{$\begin{array}{l}\text { d. CACOS represents computer-assisted construct-on-scaffold group, CACBS represents computer-assisted construct-by-self group, PAP represents } \\
\text { paper-and-pencil group, and TTE represents traditional textbook exercises group. }\end{array}$} \\
\hline \multicolumn{9}{|c|}{$\begin{array}{l}\text { e. Effect size measures the influence of the learning strategy and is computed as the mean motivation score of the post-test minus the mean motivation score } \\
\text { of the pre-test, divided by the standard deviation of the pre-test. }\end{array}$} \\
\hline
\end{tabular}

TABLE IV: ANALYSIS OF COVARIANCE IN LEARNING MOTIVATION POSTTEST SCORES FOR FOUR GROUPS

\begin{tabular}{|c|c|c|c|c|}
\hline \multirow{2}{*}{ Source of variance } & \multicolumn{4}{|c|}{ Analysis of covariance } \\
\hline & $S S$ & $d f$ & $M S$ & $F$ \\
\hline Model & 27790.14 & 4 & 6947.53 & $49.60 * * \mathrm{~h}$ \\
\hline Group & 24911.27 & 3 & 8303.76 & $59.29 * *$ \\
\hline Covariate & 3923.72 & 1 & 3923.72 & $28.01 * *$ \\
\hline Error & 19889.34 & 142 & 140.07 & \\
\hline \multirow{2}{*}{ Groups differences } & \multicolumn{4}{|c|}{ A post hoc comparison } \\
\hline & \multicolumn{2}{|c|}{ Difference in means } & \multicolumn{2}{|c|}{$t$} \\
\hline CACOS-CACBS & \multicolumn{2}{|c|}{0.41} & \multicolumn{2}{|c|}{0.16} \\
\hline CACOS-PAP & \multicolumn{2}{|c|}{17.75} & \multicolumn{2}{|c|}{$6.45^{* *}$} \\
\hline CACBS-PAP & \multicolumn{2}{|c|}{17.34} & \multicolumn{2}{|c|}{$6.29 * *$} \\
\hline CACOS-TTE & \multicolumn{2}{|c|}{31.44} & \multicolumn{2}{|c|}{$11.33 * *$} \\
\hline CACBS-TTE & \multicolumn{2}{|c|}{31.03} & \multicolumn{2}{|c|}{$11.17 * *$} \\
\hline PAP-TTE & \multicolumn{2}{|c|}{13.69} & \multicolumn{2}{|c|}{$4.87 * *$} \\
\hline
\end{tabular}

\section{B. Effects of Different Concept Mapping Techniques on Academic Achievement}

The average pretest and posttest score and effect size for each group were as follows: the CACOS group, 49.54, 81.32 and 2.22; the CACBS group, 48.83, 80.62, and 2.40; the PAP group, 50.35, 63.89, and 1.06; and the TTE group 50.93, 50.43, and -0.04 (Table III). For improving academic achievement, effect size for groups from best to worst was CACBS, CACOS, PAP, and TTE. Furthermore, two computer-assisted and paper-and-pencil concept mapping strategies all have great impact on students' academic achievement because their effect sizes are large [15]. Analysis of covariance (ANCOVA) (Table IV) indicates that differed significantly among groups $(F=59.29, p<.01)$; thus, 
different teaching strategies impacted learning achievement after controlling pre-test. Post hoc comparisons using Fisher's least significant difference (LSD) procedure indicate that students in three concept mapping groups performed significantly better $(t=11.33, p<.01 ; t=11.17, p<.01 ; t=$ $4.87, p<.01)$ than TTE group. Both computer-assisted concept mapping groups (CACOS and CACBS) performed significantly better $(t=6.45, p<.01 ; t=6.29, p<.01)$ than the PAP group. However, no significant difference $(t=0.16$, $p>0.05)$ in academic achievement existed between the CACOS and CACBS groups. The experimental results indicated that concept mapping can improve student academic achievement more than traditional textbook exercises. Furthermore, students using computer-assisted concept mapping performed significantly better than those using paper and pencil. While, no significant difference existed in academic achievement between the two groups using computer-assisted concept mapping.

\section{CONCLUSION}

This study investigated the effectiveness of different kinds of computer-assisted concept mapping on learning motivation and academic achievement. The results showed that the computer-assisted construct-on-scaffold and computer-assisted construct-by-self concept mapping strategies are more beneficial to improve students' learning motivation and academic achievement than the paper-and-pencil concept mapping and traditional textbook exercise methods and that the paper-and-pencil concept mapping is better than the traditional textbook exercise method.

\section{ACKNOWLEDGMENT}

This study is supported by the National Science Council of the Republic of China under contract No. 101-2410-H-018-026.

\section{REFERENCES}

[1] H. Hadriana, M. A. Ismail, and M. Mahdum, "The relationship between motivation self-learning and the English language achievement in secondary high school students," Asian Scoial Science, vol. 9, no. 12, pp. 36-43, 2013

[2] E. A. Linnenbrink and P. R. Pintrich, "Motivation as an enabler for academic success," School Psychology Review, vol. 31, no. 3, pp. 313-327, 2002.
[3] P. R. Pintrich and D. Schunk, Motivation in Education: Theory, Research and Applications, Upper Saddle River, NJ: Prentice-Hall Merrill, 2002.

[4] P. R. Pintrich, D. A. F. Smith, and W. J. McKeachie, "A manual for the use of the motivated strategies for learning questionnaire," Michigan: National Center for Research to Improve Postsecondary Teaching and Learning, School of Education, the University Michigan, 1989.

[5] R. Ali, A. Akhter, A. Shahzad, N. Sultana, and M. Ramzan, "The impact of motivation on students' academic achievement in mathematics in problem based learning environment," International Journal of Academic Research, vol. 3, no. 1, pp. 306-309, January 2011.

[6] H. S. Huang, C. C. Chiou, H. K. Chiang, S. H. Lai, C. Y. Huang, and Y. W. Chou, "Effects of multidimensional concept maps on fourth graders' learning in web-based computer course," Computers \& Education, vol. 58, pp. 863-873, April 2012.

[7] P. L. Liu, C. J. Chen, and Y. J. Chang, "Effects of a computer-assisted concept mapping learning strategy on EFL college students' English reading comprehension," Computers \& Education, vol. 54, pp. 436-445, February 2010

[8] P. Chularut and T. K. DeBacker, "The influence of concept mapping on achievement, self-regulation, and self-efficacy in students of English as a second language," Contemporary Educational Psychology, vol. 29, pp. 248-263, 2004

[9] D. W. Laight, "Attitudes to concept maps as a teaching / learning activity in undergraduate health professional education: Influence of preferred learning style," Medical Education, vol. 26, no. 3, pp. 29-233, 2004.

[10] K. E. Chang, Y. T. Sung, and S. F. Chen, "Learning through computer-based concept mapping with scaffolding aid," Journal of Computer Assisted Learning, vol. 17, no. 1, pp. 21-33, March 2001.

[11] P. L. Liu, "A study on the use of computerized concept mapping to assist ESL learners' writing," Computers \& Education, vol. 57, pp. 2548-2558, December 2011.

[12] D. Charsky and W. Ressler, "Games are made for fun": Lessons on the effects of concept maps in the classroom use of computer games," Computers \& Education, vol. 56, pp. 604-615, April 2011.

[13] C. W. Kaminski, "Formative use of select-and-fill-in concept map in online instruction: Implications for students of different learning styles," in Proc. the Annual International Conference of the Association for the Education of Teachers in Science. Charlotte, NC, January 10-13, 2002 (ED465604).

[14] J. D. Novak and D. B. Gowin, Learning How to Learn, New York: Cambridge University Press, 1984.

[15] J. Cohen, Statistical Power Analysis for the Behavioral Sciences, $2^{\text {nd }}$ ed., New Jersey: Lawrence Erlbaum, 1988.

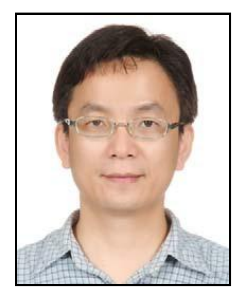

Chei-Chang Chiou completed his M.C.S. in business education at National Changhua University of Education, and Ph.D. in accounting at National Chengchi University in Taiwan. Currently, he is a professor of Department of Accounting at National Changhua University of Education. His research interest includes operating efficiency and productivity, capitalmarket, corporate governance, businesse ducation, concept mapping, and supply chain management and inventory model. 